\title{
Reversible pulmonary trunk banding. II. An experimental model for rapid pulmonary ventricular hypertrophy
}

\author{
Carlos A. Dias, MD \\ Renato S. Assad, MD \\ Luiz F. Caneo, MD \\ Maria Cristina D. Abduch, VMD \\ Vera D. Aiello, MD \\ Altamiro R. Dias, MD \\ Miguel Barbero Marcial, MD \\ Sérgio A. Oliveira, MD
}

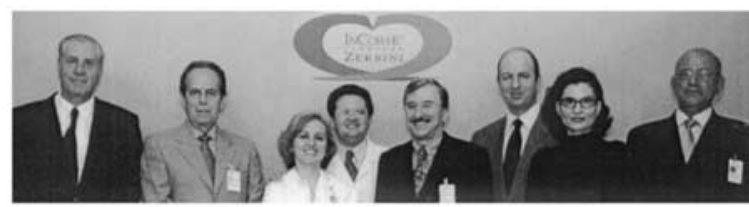

M. Barbero Marcial, S. A. Oliveira, V. D. Aiello, C. A. Dias, R. S. Assad, L. F. Caneo, M. C. D. Abduch, and A. R. Dias (left to right)
Objective: An experimental model with a reversible pulmonary trunk banding device was developed with the aim of inducing rapid ventricular hypertrophy. The device consists of an insufflatable cuff connected to a self-sealing button.

Methods: The right ventricles of 7 young goats (average weight, $8.7 \mathrm{~kg}$ ) were submitted to systolic overload and evaluated according to the hemodynamic, echocardiographic, and morphologic aspects. Baseline biopsy specimens were taken from the myocardium for microscopic analysis. The device was implanted on the pulmonary trunk and inflated so that a 0.7 right ventricular/left ventricular pressure ratio was achieved. Echocardiographic and hemodynamic evaluations were performed every 24 hours. Systolic overload was maintained for 96 hours. The animals were then killed for morphologic study. Another 9 goats (average weight, $7.7 \mathrm{~kg}$ ) were used for control right ventricular weight.

Results: The systolic right ventricular/pulmonary trunk pressure gradient varied from $10.1 \pm 4.3 \mathrm{~mm} \mathrm{Hg}$ (baseline) to $60.0 \pm 11.0 \mathrm{~mm} \mathrm{Hg}$ (final). Consequently, the right ventricular/left ventricular pressure ratio increased from $0.29 \pm 0.06$ to $1.04 \pm$ 0.14 . The protocol group showed a $74 \%$ increase in right ventricular mass when compared with the control group. Serial 2-dimensional echocardiography showed a $66 \%$ increase in right ventricular wall thickness. There was a $24 \%$ increase in the mean myocyte perimeter, and the myocyte area increased $61 \%$.

From the Heart Institute University of São Paulo Medical School, São Paulo, Brazil.

Read at the 9th Biennial Meeting of the Society of Pediatric Cardiovascular Surgery Aldo R. Castañeda, Boston, Mass, April 2000.

Received for publication Oct 18, 2001; revisions requested Jan 2, 2002; revisions received Feb 8, 2002; accepted for publication Feb 16, 2002.

Address for reprints: Renato Assad, MD, Heart Institute University of São Paulo, Division of Surgery, Ave Dr Eneas de Carvalho Aguiar, 44, São Paulo, SP 05403000, Brazil (E-mail: rsassad@cardiol.br).

J Thorac Cardiovasc Surg 2002;124: 999-1006

Copyright (C) 2002 by The American Association for Thoracic Surgery

0022-5223/2002 $\$ 35.00+0 \quad \mathbf{1 2 / 1 / 1 2 4 2 3 4}$

doi: $10.1067 / \mathrm{mtc} .2002 .124234$
Conclusions: The device is easily adjustable percutaneously, enabling right ventricular hypertrophy in 96 hours of gradual systolic overload. This study suggests that the adjustable pulmonary trunk banding might provide better results for the 2-stage Jatene operation and for the failed atrial switch operations to convert to the double-switch operation.

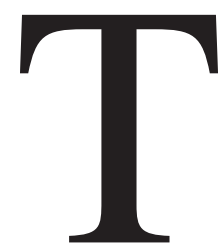

he Jatene operation is the treatment of choice for transposition of the great arteries (TGA). ${ }^{1,2}$ Retraining of the left ventricle is necessary in patients with TGA beyond the neonatal period and in congenitally corrected TGA or after Senning or Mustard operations with right ventricular (RV) failure. In these cases the repair should be performed in 2 stages. ${ }^{3,4}$

We still have a considerable number of patients with late referral for the Jatene operation. However, we were not able to reproduce the excellent Boston experience of rapid left ventricular (LV) preparation, ${ }^{4}$ probably related to the lack of pulmonary 


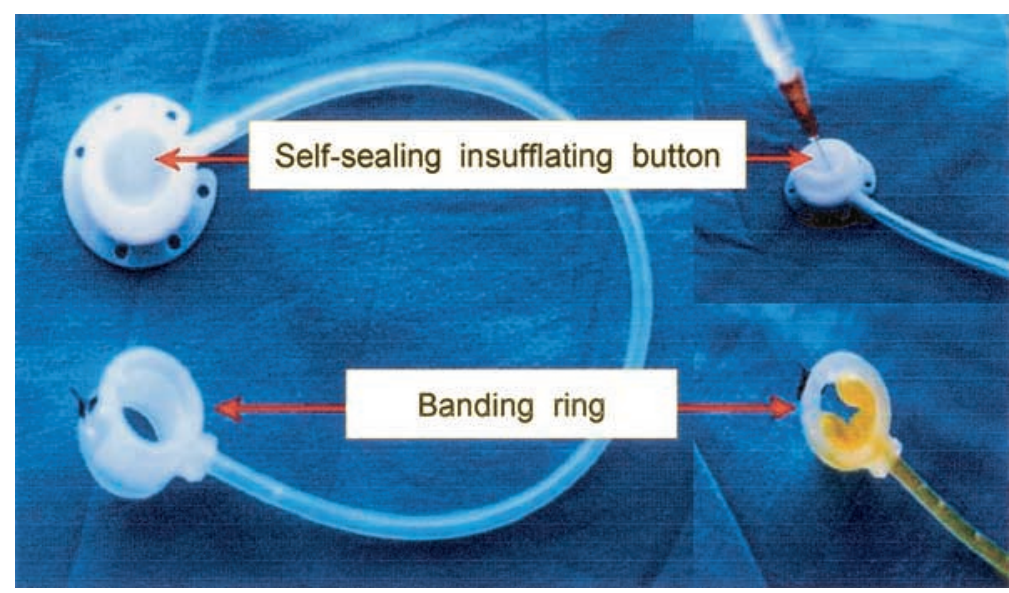

Figure 1. PT banding device consisting of 3 parts: banding ring, extension tube, and self-sealing inflation button.

trunk (PT) banding adjustment, which has been done empirically. The degree of PT banding might be inadequate or imprecise, causing an important acute systolic overload on the left ventricle, which in turn would impair late ventricular function. ${ }^{5-8}$

We developed an experimental model designed to adjust PT banding percutaneously and to induce rapid pulmonary ventricular hypertrophy. The RV changes caused by the PT banding device were evaluated according to hemodynamic, echocardiographic, and morphologic aspects after 96 hours of uninterrupted gradual systolic overload.

\section{Materials and Methods \\ Anesthesia}

Seven young goats, 30 to 60 days old and with a mean weight of $8.7 \pm 2.4 \mathrm{~kg}$, were studied. Another 9 goats, with similar age and a mean weight of $7.7 \pm 1.2 \mathrm{~kg}$, were used as a control group for $\mathrm{RV}$ weight evaluation. Anesthesia was induced with ketamine (50 $\left.\mathrm{mg} \cdot \mathrm{kg}^{-1}\right)$. A jugular venous line was placed for drug infusions. Each animal was then sedated with pentobarbital sodium (Nembutal; 5 -10 $\mathrm{mg} \cdot \mathrm{kg}^{-1}$ administered intravenously) and then ventilated through a tracheal tube with $100 \%$ oxygen (Harvard 708). Electrocardiographic and blood pressure measurements were taken through computer software (ACQknowledge 3.01, Biopac Systems, Inc). The goat was then prepared for sterile surgical procedure. Goats received $500 \mathrm{mg}$ of cefazolin and $10 \mathrm{mg}$ of gentamicin intramuscularly every 12 hours, beginning just before the operation.

\section{PT Banding Device}

Figure 1 shows the 3 components of the banding device: banding ring, extension tube, and insufflation button. The banding ring (Hazen Everett Co) is a U-shaped hydraulic cuff with a $10-\mathrm{mm}$ internal diameter and a 5-mm width. Its outer layer consists of 1-mm-thick rigid silicone, which keeps it from deforming. The inner surface has a deformable layer of silicone, which expands, compressing the lumen of the vessel according to the volume injected into the inflation button. At the 2 ends of the cuff, there are small orifices that are used for securing the ring to the PT. The extension tube, also made of silicone, links the banding ring with the insufflation button. It has a 2-mm inner diameter and is $25 \mathrm{~cm}$ long. The inflation button (Bard Access System) is a circular reservoir made of self-sealing silicone, the base of which includes a metal plate. The reservoir has a port, which is connected to the extension tube. This button is implanted subcutaneously, thus permitting the inflation or deflation of the banding ring percutaneously.

\section{Procedure}

The chest was opened at the fourth left intercostal space to expose the descending aorta and the RV outflow tract. A purse-string suture (5-0 polypropylene) was placed in the aorta to insert a 16-gauge catheter (Bard Co) for systemic blood pressure monitoring. Two additional 16-gauge catheters were implanted, one in the right ventricle and another distally in the PT, and fixed in position with a 5-0 polypropylene purse-string suture. All the catheters were kept heparinized and then exteriorized through the chest wall. The PT was then dissected free for banding device placement. The banding ring was wrapped around the PT, and its ends were sutured together and secured on the adventitia with polypropylene 5-0 sutures just above the pulmonary valve level. The extension tube of the banding ring was brought out through the third intercostal space and connected to the insufflation button, which was lodged subcutaneously in the chest wall. The inflation button was tested, and all of the air in the system was evacuated. The ribs were approximated after placing a small drainage catheter in the left pleural space, and the soft tissues were closed. After 4 to 6 hours of postoperative care, the pleural catheter was then removed.

\section{Echocardiographic Studies}

All examinations included 2-dimensional and M-mode echocardiographic imaging of the ventricles from the right parasternal view with 2.5- and 5-MHZ transducers (Ultramark 4, Advanced Technology Laboratories). Initial evaluation confirmed a RV free wall thickness smaller than that of the left ventricle. Postoperative 
TABLE 1. Hemodynamic data before and after the 96 -hour systolic overload of the right ventricle $(n=7)$

\begin{tabular}{|c|c|c|c|c|c|}
\hline $\begin{array}{l}\text { RV systolic } \\
\text { overload }\end{array}$ & $\begin{array}{l}\text { Heart rate } \\
\text { (beats/min) }\end{array}$ & $\begin{array}{l}\text { Systemic systolic } \\
\text { pressure (mm Hg) }\end{array}$ & $\begin{array}{c}\text { RV systolic } \\
\text { pressure (mm Hg) }\end{array}$ & $\begin{array}{c}R V \\
\text { gradient }(\mathrm{mm} \mathrm{Hg})\end{array}$ & $\begin{array}{c}\mathrm{RV} / \mathrm{LV} \\
\text { pressure ratio }\end{array}$ \\
\hline Baseline & $127.9 \pm 12.5$ & $79.4 \pm 6.1$ & $22.4 \pm 4.1$ & $10.1 \pm 4.3$ & $0.29 \pm 0.06$ \\
\hline $96 \mathrm{~h}$ & $150.0 \pm 8.7$ & $68.6 \pm 3.6$ & $71.0 \pm 10.0$ & $60.0 \pm 11.0$ & $1.04 \pm 0.14$ \\
\hline$P$ value & .01 & .005 & .0001 & .0001 & .0001 \\
\hline
\end{tabular}

Values are presented as means \pm SD.

evaluation of induced hypertrophy was performed with intervals of 24 hours. The following parameters were observed: (1) RV, LV, and septal wall thicknesses; (2) RV/PT pressure gradient; and (3) presence of effusions.

\section{Protocol}

All animals received humane care in compliance with the "Principles of Laboratory Animal Care" formulated by the National Society for Medical Research and the "Guide for the Care and Use of Laboratory Animals" prepared by the National Academy of Sciences and published by the National Institutes of Health. Digoxin was given to all goats $\left(0.5 \mu \mathrm{g} \cdot \mathrm{kg}^{-1} \cdot \mathrm{d}^{-1}\right.$ administered intramuscularly). The inflation protocol of progressive RV systolic overload was begun after full surgical recovery. After taking baseline pressure measurements, the PT banding device was initially inflated by means of percutaneous injection of saline solution with a 1-mL syringe under sterile conditions to achieve a 0.7 $\mathrm{RV} / \mathrm{LV}$ systolic pressure ratio, as long as it did not cause more than a $10 \%$ systemic pressure drop. The amount of water used for cuff inflation varied from 0.1 to $0.4 \mathrm{~mL}$. The volume in the banding device was progressively incremented at 24-hour intervals, according to animal tolerance to the pressure load. If systemic hypotension, respiratory distress, or both developed after inflation of the banding device, it was deflated to the previous volume compatible with maintenance of goat hemodynamics. Hemodynamic evaluation was performed every 24 hours. The RV systolic overload was carried out for 96 hours. The animals were then killed for morphologic evaluation of the heart.

\section{Morphologic Studies}

Baseline myocardial samples ( $3 \mathrm{~mm}$ maximal diameter) from the subepicardial layer of the RV outflow tract were collected for optical microscopic studies just before catheter insertion. After 96 hours of RV systolic overload, the animals were killed, and the positions of the catheters were checked in the right ventricle, PT, and aorta. The hearts were then removed from the thorax. Similarly, the control group animals were also killed to measure the ventricular and septal weights.

Weight determinations. The ventricular and septal weights were taken according to the Fulton technique (METTLER AE-200, Mettler-Toledo AG). ${ }^{9}$ The weight measurements were indexed to the body weight of the animal (in grams per kilogram), as suggested by Bishop and Cole. ${ }^{10}$

Optical microscopy. After weight measurements, the hearts were fixed in $10 \%$ buffered formalin for 24 hours. A transverse cut of the ventricular mass was made $1 \mathrm{~cm}$ below the level of the atrioventricular junction. Sections from the ventricular septum, right ventricle, and left ventricle were obtained. After routine histologic processing, 5- $\mu \mathrm{m}$ sections were stained with hematoxylin and eosin. The perimeter and area of transversely sectioned cardiomyocytes were measured at the level of the nucleus by means of an image analysis system (Quantimet-Leica, Leica Cambridge Ltd) at a magnification of $400 \times$. Data were collected from 140 myocytes of baseline samples and from 105 myocytes of the ventricles subjected to 96 hours of RV systolic overload.

\section{Statistical Analysis}

Values are expressed as means $\pm \mathrm{SD}$. The paired Student $t$ test was used to compare the baseline data with the 96-hour data of the RV systolic overload group under hemodynamic, echocardiographic, and optical microscopy aspects. The unpaired Student $t$ test was used (GB-STAT, Dynamic Microsystems) to compare the septal and ventricular weights. The statistical significance was set at $5 \%$ level.

\section{Results}

During the protocol, the animals remained active, with no clinical signs of RV decompensation. All the implanted devices functioned adequately for water injection and suction. No migration or rupture of the device was noted nor was there any injury to the adjacent structures caused by the cuff or leaks through the single connection between the extension tube and the self-sealing insufflation button.

\section{Hemodynamic Measurements}

All the animals presented with tachycardia at the end of the protocol (baseline, $127.9 \pm 12.5$ beats/min; after 96 hours of systolic overload, $150.0 \pm 8.7$ beats $/ \mathrm{min} ; P=.003)$. We noticed a $13.6 \%$ decrease in the aortic systolic pressure during the protocol, although no changes in $\mathrm{LV}$ function were observed with echocardiography $(P=.005)$.

After 96 hours of systolic overload, the right ventricle showed a $217.0 \%$ increase in systolic pressure, from $22.4 \pm$ $4.1 \mathrm{~mm} \mathrm{Hg}$ to $71.0 \pm 10.0 \mathrm{~mm} \mathrm{Hg}$, surpassing the systolic pressure of the left ventricle $(P=.0001)$. The RV/PT systolic gradient varied from $10.1 \pm 4.3 \mathrm{~mm} \mathrm{Hg}$ to $60.0 \pm$ $11.0 \mathrm{~mm} \mathrm{Hg}(P=.0001)$, whereas the $\mathrm{RV} / \mathrm{LV}$ pressure ratio increased from $0.29 \pm 0.06$ (before RV systolic overload) to $1.04 \pm 0.14$ (after the 96-hour protocol, $P=.0001$ ). The hemodynamic data are summarized in Table 1.

Table 2 shows the time course of RV/LV pressure ratio response for each animal. At the initial banding, 3 animals (nos. 2, 3, and 5) did not achieve a desired level of banding. 
TABLE 2. Time course of RV/LV pressure ratio response for each animal

\begin{tabular}{|c|c|c|c|c|c|c|c|c|c|}
\hline \multicolumn{10}{|c|}{ Period of protocol (h) } \\
\hline \multirow[b]{2}{*}{ Animal } & \multicolumn{2}{|c|}{ Baseline } & \multicolumn{2}{|c|}{24} & \multicolumn{2}{|c|}{48} & \multicolumn{2}{|c|}{72} & \multirow{2}{*}{$\frac{96}{\text { Found }}$} \\
\hline & Found & Left & Found & Left & Found & Left & Found & Left & \\
\hline 1 & 0.32 & 0.81 & 0.49 & 0.89 & 0.75 & 0.90 & 0.80 & 1.10 & 1.00 \\
\hline 2 & 0.20 & 0.48 & 0.32 & 0.59 & 0.27 & 0.73 & 0.42 & 0.95 & 1.01 \\
\hline 3 & 0.24 & 0.61 & 0.33 & 0.96 & 0.56 & 1.04 & 1.07 & 1.07 & 1.01 \\
\hline 4 & 0.28 & 0.69 & 0.51 & 0.77 & 0.44 & 0.94 & 1.33 & 1.33 & 1.13 \\
\hline 5 & 0.23 & 0.51 & 0.36 & 0.71 & 0.32 & 0.71 & 0.53 & 0.56 & 0.79 \\
\hline 6 & 0.35 & 0.93 & 0.80 & 0.91 & 0.84 & 0.96 & 0.97 & 1.11 & 1.09 \\
\hline 7 & 0.37 & 0.93 & 0.88 & 0.92 & 0.80 & 1.05 & 0.93 & 1.06 & 1.22 \\
\hline
\end{tabular}

Values are RV/LV pressure ratios of each animal subjected to 96 hours of systolic overload of the RV. Found, Pressure ratio encountered during daily measurements before adjustments; left, daily pressure ratio adjusted.

The RV/LV pressure ratios were $0.48,0.61$, and 0.51 , respectively. During the protocol, 2 animals did not tolerate more banding at 72 hours (animal 3, RV/LV ratio of 1.07; animal 4, RV/LV ratio of 1.33). Nevertheless, RV hypertrophy was achieved in all of the animals.

\section{Echocardiographic Findings}

Table 3 shows the echocardiographic data before and after $\mathrm{RV}$ overload. We observed a $66 \%$ increase in the RV free wall thickness (from $4.4 \pm 0.5 \mathrm{~mm}$ to $7.3 \pm 1.7 \mathrm{~mm}, P=$ $.002)$, surpassing that of the LV free wall and the septum $(5.1 \pm 0.4 \mathrm{~mm})$. There were no significant changes in the septum and LV free wall thicknesses. The RV/PT pressure gradient, measured by means of Doppler echocardiography, increased from $10.6 \pm 5.4 \mathrm{~mm} \mathrm{Hg}$ before the protocol to $74.9 \pm 9.7 \mathrm{~mm} \mathrm{Hg}$ after the 96-hour period of systolic overload $(P=.0001)$. The catheter pressure gradient measurements are overestimated by $5 \%$ before the protocol and by $25 \%$ at the end of 96 hours of systolic overload. Pleural effusions were found in all the animals.

\section{Morphologic Findings}

The intimal surface of the PT appeared normal. None of the animals demonstrated macroscopic thickening of the pulmonary valve.

Weight of the ventricles. The RV weight from the studied animals was $74 \%$ greater than that from the control group $(0.99 \pm 0.17 \mathrm{vs} 1.72 \pm 0.24 \mathrm{~g} / \mathrm{kg}, P=.0001)$. There was no difference between the septal and LV weights from the studied animals compared with those in the control group. These weight measurements are summarized in Table 4 .

Optical microscopy. Table 5 shows the results of the perimeter and area of the cardiac fibers measured before and after the RV systolic overload. A $27 \%$ increase in the perimeter of the RV myocyte was found after 96 hours of systolic overload (from $45.9 \pm 4.5 \mu \mathrm{m}$ for the baseline condition to $58.3 \pm 9.3 \mu \mathrm{m}$ after the protocol, $P<.0001$ ). Figure 2 presents representative pictures of the RV cardiac myocytes of animal 6 before and after the protocol. We noted a $69 \%$ increase of the cardiac myocyte area after the protocol (from $132.2 \pm 25.4 \mu \mathrm{m}^{2}$ for the baseline condition to $223.5 \pm 72.1 \mu \mathrm{m}^{2}$ after the protocol, $\left.P<.0001\right)$. We did not observe significant signs of interstitial fibrosis or extracellular edema.

\section{Discussion}

The device presented in this study represents an alternative approach not only for the LV rapid preparation in patients with TGA and intact ventricular septum beyond the neonatal period but also in converting the failed Mustard or Senning procedure to the Jatene operation or in congenitally corrected TGA with RV failure. ${ }^{11-13}$ It was designed for variable and reversible manipulation of the subpulmonary ventricular afterload, regardless of the time required to achieve that manipulation. Thus a progressive systolic overload can be applied to the subpulmonary ventricle, limiting the abruptness of the acute stenosis imposed during conventional PT banding.

\section{Critique of the Preparation}

This protocol analyzes some aspects of the acute RV hypertrophy in a young animal model. At the present time, it is not clear whether the response to the stimulus of the variable systolic overload on the subpulmonary ventricle of adult animals would be the same. In the clinical setting the hypertrophic response of the subpulmonary ventricle has been demonstrated to take a longer time. According to Mavroudis and Backer, ${ }^{12}$ patients with TGA and failed atrial inversion aged from 1.9 to 23 years took an average of 15.6 months to retrain the subpulmonary ventricle for the 2 -stage Jatene operation. Ongoing studies in our laboratory are assessing this protocol in an adult model. Blood oximetry changes induced by PT banding were not evaluated in this study. However, no clinical signs of significant hypoxia, acidosis, or both were observed. Although a more precise adjustment of RV systolic overload could be 
TABLE 3. Echocardiographic findings before and after the 96 -hour systolic overload of right ventricle $(\mathrm{n}=7)$

\begin{tabular}{lcccc}
\hline $\begin{array}{l}\boldsymbol{R} V \text { systolic } \\
\text { overload }\end{array}$ & $\begin{array}{c}\boldsymbol{R V} \text { free wall } \\
(\mathbf{m m})\end{array}$ & $\begin{array}{c}\text { Interventricular } \\
\text { septum }(\mathbf{m m})\end{array}$ & $\begin{array}{c}\text { LV free wall } \\
(\mathbf{m m})\end{array}$ & $\begin{array}{c}\boldsymbol{R} \text { /PT gradient } \\
(\mathbf{m m} \text { Hg) }\end{array}$ \\
\hline Baseline & $4.4 \pm 0.5$ & $4.9 \pm 0.4$ & $5.4 \pm 0.5$ & $10.6 \pm 5.4$ \\
96 h & $7.3 \pm 1.7$ & $5.1 \pm 0.4$ & $5.1 \pm 0.4$ & $74.9 \pm 9.7$ \\
$P$ value & .002 & $\mathrm{NS}$ & $\mathrm{NS}$ & .0001 \\
\hline
\end{tabular}

Values are presented as means \pm SD. NS, Not significant.

achieved, this model does not reflect the clinical reality of patients with TGA and a functionally intact ventricular septum. PT banding might not be tolerated in patients with significant hypoxia without a Blalock-Taussig shunt. Nevertheless, the adjustability of PT banding could favor a balanced interatrial shunt in patients with TGA, thus avoiding the Blalock-Taussig shunt. Furthermore, the device could be disinsufflated at any time if serious hypoxia occurs.

\section{Historical Notes}

Some of the historical aspects conceptually related to our prototype are described here. The idea of an adjustable banding device composed of a hydraulic cuff and a selfsealing button was first proposed in 1957. In fact, Jacobson and McAllister ${ }^{14}$ proposed a device that consisted of a rubber cuff with a lateral opening connected to a reservoir protected by self-sealing rubber. It was used on the great vessels of dogs, aiming at a congestive heart failure model. Complications in handling the device were observed. In 1969, Bishop and Cole ${ }^{10}$ improved Jacobson and McAllister's device by covering the cuff with silicone, with the aim of reducing local tissue reaction. They induced RV hypertrophy and congestive heart failure in a dog model. In 1972, Edmunds and associates ${ }^{15}$ introduced 2 main changes: an external, nondeformable layer on the hydraulic cuff and use of silicone instead of rubber. However, they observed asymmetric inflation or rupture of the cuff, and leakage of the injected material prevented clinical use. In 1985, a new device made of biologically stable material (medical grade silicone) was introduced by Park and colleagues. ${ }^{16}$ The cuff was covered with reinforced braid and coated with silicone. The self-sealing button had a silicone diaphragm that did enable repeated needle puncture, avoiding leakage through the button. The device implanted in dogs and lambs was easily and effectively adjusted. In that same year, Solis and coworkers, ${ }^{17}$ for the first time in the literature, proposed a similar device to the previous one that was intended to prepare the subpulmonary ventricle for the 2-stage Jatene operation. Nevertheless, when the system was submitted to a high gradient pressure, as in the systemic circulation, dilation of the reservoir and the connecting tube occurred. In addition, there was a tendency of the cuff to bulge laterally under high pressure. In another study the same group improved the strength of the material by reinforcing the cuff
TABLE 4. Weight measurements of cardiac muscle mass indexed to body weight (in grams per kilogram)

\begin{tabular}{lccc}
\hline Animals & $\boldsymbol{R V}$ & $\boldsymbol{I V S}$ & $\boldsymbol{L V}$ \\
\hline Control & $0.99 \pm 0.17$ & $1.24 \pm 0.22$ & $1.68 \pm 0.35$ \\
Trained & $1.72 \pm 0.24$ & $1.32 \pm 0.20$ & $1.69 \pm 0.16$ \\
$P$ value & .0001 & $\mathrm{NS}$ & $\mathrm{NS}$ \\
\hline
\end{tabular}

Values are presented as means $\pm S D$ (control group, $n=9$; trained group [subjected to 96 hours of systolic overload of the RV], $\mathrm{n}=7$ ) IVS, Interventricular septum; $N S$, not significant.

TABLE 5. Cardiac myocyte perimeter and area measurements before and after the RV systolic overload protocol (Quantimet-Leica image analysis system; original magnification $400 \times ; n=7$ )

\begin{tabular}{lcc}
\hline $\begin{array}{l}\text { RV } \text { systolic } \\
\text { overload }\end{array}$ & $\begin{array}{c}\text { RV } \text { myocyte } \\
\text { perimeter }(\mathbf{m m})\end{array}$ & $\begin{array}{c}\boldsymbol{R} \text { V myocyte } \\
\text { area }(\mathbf{m m})\end{array}$ \\
\hline Baseline & $45.9 \pm 4.5$ & $132.2 \pm 25.4$ \\
$96 \mathrm{~h}$ & $58.3 \pm 9.3$ & $223.5 \pm 72.1$ \\
$P$ value & $<.0001$ & $<.0001$ \\
\hline
\end{tabular}

Values are presented as means \pm SD.

and the connecting tube with a spiral of 4-0 silk to withstand systemic arterial pressure. ${ }^{18}$ Again, they experienced bulging of the cuff caused by a loosening silk. In our study the gradient imposed by the cuff was steady, and such deformation was not observed because of a rigid and thick cuff outer layer, which avoided centrifugal distortion when insufflated.

\section{Echocardiographic Aspects}

In our protocol the calculated pressure gradients from Doppler velocities overestimated the directly measured gradients from implanted catheters. This situation could be compared with the Venturi effect, which allows almost complete pressure recovery after the stenotic area at the vena contracta. Our data are corroborated by the in vitro studies of Levine and associates, ${ }^{19}$ which have demonstrated a greater poststenotic pressure recovery, measured directly with a catheter, related to the extent of the obstruction, which in turn lowers the pressure gradient. These data suggest an important advantage for Doppler gradient estimation, which uses the peak velocity and provides the 


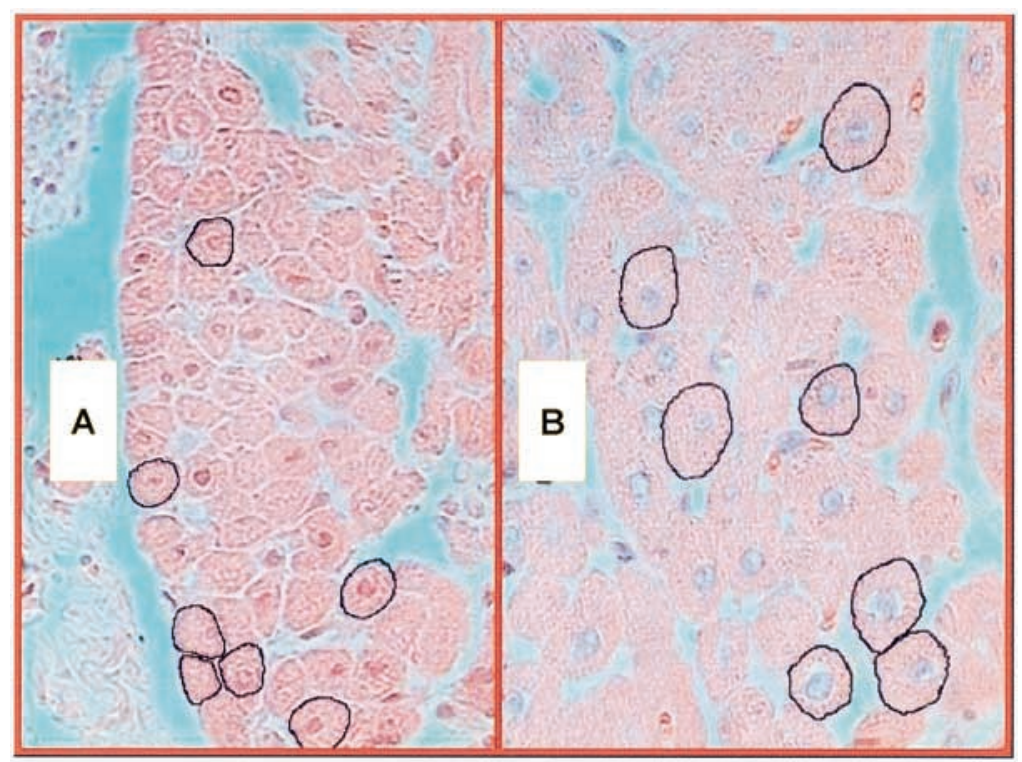

Figure 2. Microphotography of RV cardiac myocytes of animal 6 sectioned transversely at the level of the nucleus, indicating their perimeters and respective areas: $A$, baseline samplings; $B$, samplings after 96 hours of systolic overload. (Original magnification $400 \times$.)

maximum gradient at the vena contracta, which determines the load imposed on the proximal chamber.

\section{Morphologic Aspects}

The important increase in the overloaded RV weight could reflect an increase in water content of the myocardium. Under microscopic analysis, however, there was no evidence of significant edema or interstitial fibrosis. Studies by Katayama and coworkers ${ }^{20}$ showed that the increase in the ventricular weight subjected to a 4-day period of intermittent systolic overload was associated with an increase in the dry weight of the myocardium, relating such findings to hypertrophy of the cardiac myocyte rather than edema. However, the magnitude of hypertrophy needed for the Jatene operation remains unclear. Regarding the microscopic analysis, the myocyte perimeter and area measurements at the level of the nucleus are based on the studies of Anversa and colleagues. ${ }^{21}$ These authors analyzed cardiac myocytes of rats subjected to 20 hours of constriction of the abdominal aorta. It was noted that in addition to the increase in the protein synthesis in the myocytes, there was a $20 \%$ increase in their area. During a longer period (13 days) of similar systolic overload, those authors found an increase of more than 200\% in the average cross-sectional area of the cardiac myocytes of rats. ${ }^{22}$ Data obtained in our laboratory ${ }^{23}$ using a balloon catheter to induce the RV hypertrophy of young goats for a variable period of 9 to 20 days showed a $20 \%$ increase in the diameter (not the area) of the cardiac myocytes. In the present study the 96 hours of RV systolic overload induced a 69\% increase in the myocyte area, which was enough to generate systemic pressures in the right ventricle. Actually, the ideal time and way of preparing the subpulmonary ventricle for the 2-stage Jatene operation remains controversial. There is evidence that nongradual and abrupt banding, causing sudden and acute systolic overload, could induce significant damage to the myocardium. A subpulmonary ventricle training program in a fashion tailored to the ventricle response should be established similarly to a fitness program tailored to an athlete, as mentioned by Redington, ${ }^{24}$ thus avoiding the pathologic hypertrophy. Therefore an adjustable banding device would be advantageous for optimal ventricular training.

\section{Implications}

In our protocol a $0.7 \mathrm{RV} / \mathrm{LV}$ pressure ratio, a maximum $10 \%$ decrease in systemic systolic pressure, or both were used as parameters for device inflation. Other authors have used subjective criteria, such as animal clinical condition or signs of RV failure. Clinically, other parameters to indicate primary correction of TGA include a systolic subpulmonary ventricular pressure of greater than $65 \mathrm{~mm} \mathrm{Hg}^{25}$ or an LV/RV systolic pressure ratio of greater than $0.75,{ }^{26}$ although Däbritz and associates ${ }^{27}$ have performed primary Jatene operations in a series of 7 patients aged 4 weeks or older with a pulmonary/systemic pressure ratio of 0.2 to 0.5 after submitting a trial of PT banding to systemic pressure for 15 to 30 minutes. Previous studies from our laboratory have demonstrated an equalization of ventricular thickness over a short interval of 6 to 10 days of more gradual balloon inflation ${ }^{24}$ compared with the 96-hour period of the systolic 
overload of the present study. It is noteworthy that some of the animals had systemic pressure in the subpulmonary ventricle with only 48 hours of systolic overload. However, Boutin and coworkers ${ }^{5}$ associate the late LV dysfunction with an extremely acute overload in patients undergoing the 2-stage Jatene operation. Such dysfunction was inversely proportional to more rapid hypertrophy and to more serious dysfunction after PT banding. On the other hand, patients who present with systemic ventricular failure in corrected TGA or after failed atrial baffle operations almost always have associated tricuspid regurgitation. It is not clear whether this association is a cause or a consequence of ventricular failure. Different groups have demonstrated clinical recovery of RV function and resolution of tricuspid regurgitation after the 2-stage Jatene operation as an alternative to cardiac transplantation. ${ }^{12,13,28,29}$ However, reoperations to tighten or loosen the band were necessary in some cases to prepare the left ventricle to tolerate systemic pressure. We believe that the adjustability of the hydraulic cuff might be more effective in training the subpulmonary ventricle in a shorter time, not only by avoiding reoperations for band adjustment but also by allowing the fine tuning of the systolic overload over that ventricle in response to a patient's hemodynamic status. Perhaps our model of variable and progressive systolic overload could favor a healthier hypertrophy of the subpulmonary ventricle when compared with the conventional stationary banding, in which the systolic stress is abrupt and constant. The gradual increase of the RV overload allowed not only progressive tolerance to the PT banding but also generated pressures even greater than that of the left ventricle after the training period. Future studies using molecular biology as a tool to assess markers of pathologic hypertrophy might compare several training programs for the subpulmonary ventricle. The main goal would be minimum cellular damage and maximum efficiency of the pulmonary banding.

\section{Conclusion}

The device proposed in this article is biocompatible and easily implanted. It was efficient in performing the adjustable PT banding percutaneously. The systolic overload imposed by the device enabled the rapid hypertrophy ( 96 hours) of the subpulmonary ventricles of the animals studied. This treatment might allow the preparation of the subpulmonary ventricle for the 2-stage Jatene operation not only in patients with TGA beyond the neonatal period but also in those who present with systemic ventricular failure in corrected TGA or after failed atrial baffle operations.

We thank Nelson Correa, Jr, laboratory technician, for his collaboration during the protocol.

\section{References}

1. Jatene AD, Fontes VF, Paulista PP, de Souza LC, Neger F, Galantier $\mathrm{M}$, et al. Successful anatomic correction of transposition of the great vessels: a preliminary report. Arq Bras Cardiol. 1975;28:461-4.

2. Jatene AD, Fontes VF, Paulista PP, Souza LC, Neger F, Galantier M, et al. Anatomic correction of transposition of the great vessels. J Thorac Cardiovasc Surg. 1976;72:364-70.

3. Yacoub MH, Radley-Smith R, MacLaurin R. Two-stage operation for anatomical correction of transposition of the great arteries with intact interventricular septum. Lancet. 1977;1:1275-8.

4. Jonas RA, Giglia TM, Sanders S, Wernovsky G, Nadal-Ginard B, Mayer JE Jr, et al. Rapid, two-stage arterial switch for transposition of great arteries and intact ventricular septum beyond the neonatal period. Circulation. 1989;80(suppl I):I203-8.

5. Boutin C, Wernovsky G, Sanders SP, Jonas RA, Castaneda AR, Colan SD. Rapid two-stage arterial switch operation. Evaluation of left ventricular systolic mechanics late after an acute pressure overload stimulus in infancy. Circulation. 1994;90:1294-303.

6. Redington AN. Functional assessment of the heart after corrective surgery for complete transposition. Cardiol Young. 1991;1:84-90.

7. Sandor GS, Freedom RM, Williams WG, LeBlanc J, Trusler G, Patterson MW, et al. Left ventricular systolic and diastolic function after two-stage anatomic correction of transposition of the great arteries. Am Heart J. 1988;115:1257-62.

8. Sievers HH, Lange PE, Onnasch DG, Radley-Smith R, Yacoub MH, Heintzen PH, et al. Influence of the two-stage anatomic correction of simple transposition of the great arteries on left ventricular function. Am J Cardiol. 1985;56:514-9.

9. Fulton RM, Hutchinson EC, Jones AM. Ventricular weight in cardiac hypertrophy. Br Heart J. 1952;14:413-20.

10. Bishop SP, Cole CR. Production of externally controlled progressive pulmonic stenosis in the dog. $J$ Appl Physiol. 1969;26:659-63.

11. Mee RBB. Severe right ventricular failure after Mustard or Senning operation. Two-stage repair: pulmonary artery banding and switch. J Thorac Cardiovasc Surg. 1986;92:385-90.

12. Mavroudis C, Backer CL. Arterial switch after failed atrial baffle procedures for transposition of the great arteries. Ann Thorac Surg. 2000;69:851-7.

13. Van Son JAM, Reddy M, Silverman NH, Hanley FL. Regression of tricuspid regurgitation after two-stage arterial switch operation for failing systemic ventricle after atrial inversion operation. $J$ Thorac Cardiovasc Surg. 1996;111:342-7.

14. Jacobson JH, McAllister FF. A method for the controlled occlusion of a larger blood vessel. Ann Surg. 1957;145:334-43.

15. Edmunds LH Jr, Rudy LW, Heymann MA, Boucher JK. An adjustable pulmonary arterial band. Trans Am Soc Artif Int Organs. 1972;18: 217-25.

16. Park SC, Griffith BP, Siewers RD, Hardesty RL, Ladowsky J, Zoltum RA, et al. A percutaneously adjustable device for banding of the pulmonary trunk. Int J Cardiol. 1985;9:477-84.

17. Solis E, Heck CF, Seward JB, Kaye MP. Percutaneously adjustable pulmonary artery band. Ann Thorac Surg. 1986;41:65-9.

18. Solis E, Bell D, Alboliras H, Seward J, Kaye MP. Left ventricular preparation with an extrathoracically adjustable balloon occluder. Ann Thorac Surg. 1987;44:58-61.

19. Levine RA, Jimoh A, Cape EG, McMillan S, Yoganathan AP, Weyman AE. Pressure recovery distal to a stenosis: potential cause of gradient "overestimation" by Doppler echocardiography. J Am Coll Cardiol. 1989;13:706-15.

20. Katayama H, Krzeski R, Frantz EG, Ferreiro JI, Lucas CL, Ha B, et al. Induction of right ventricular hypertrophy with obstructing balloon catheter: nonsurgical ventricular preparation for the arterial switch operation in simple transposition. Circulation. 1993;88:1765-9.

21. Anversa P, Vitali-Mazza L, Gandolfi A, Loud AV. Morphometry and autoradiography of early hypertrophic changes in the ventricular myocardium of adult rat. A light microscopic study. Lab Invest. 1975;33: 125-9.

22. Anversa P, Hagopian M, Loud AV. Quantitative radioautographic localization of protein synthesis in experimental cardiac hypertrophy. Lab Invest. 1973;29:282-7. 
23. Assad RS, Cardarelli M, Abduch MC, Aiello VD, Maizato M, Barbero Marcial M, et al. Reversible pulmonary trunk banding with a balloon catheter: assessment of rapid pulmonary ventricular hypertrophy. J Thorac Cardiovasc Surg. 2000;120:66-72.

24. Redington A. Alternatives for LV training. CTSNet Discussion Forum, Annals of Thoracic Surgery, 2000. Arterial switch after failed atrial baffle procedures for transposition of the great arteries. Available at: http://www.ctsnet.org/forum/123/0/2862.

25. Yasui H, Kado H, Yonenaga K, Hisahara M, Ando H, Iwao H, et al. Arterial switch operation for transposition of the great arteries, with special reference to left ventricular function. J Thorac Cardiovasc Surg. 1989;98:601-10.
26. Jonas RA. Update on the rapid two-stage arterial switch procedure. Cardiol Young. 1991;1:99-100.

27. Dabritz S, Engelhardt W, von Bernuth G, Messmer BJ. Trial of pulmonary artery banding: a diagnostic criterion for 'one-stage' arterial switch in simple transposition of the great arteries beyond the neonatal period. Eur J Cardiothorac Surg. 1997;11:112-6.

28. Cochrane AD, Karl TR, and Mee RB. Staged conversion to arterial switch for late failure of the systemic right ventricle. Ann Thorac Surg. 1993;56:854-61.

29. Poirer NC and Mee RBB. Left ventricular reconditioning and anatomical correction for systemic right ventricular dysfunction. Semin Thorac Cardiovasc Surg Pediatr Card Surg Annu. 2000;3:198-215. 